\title{
The Effect of Viscosity on Performance of a Low Specific Speed Centrifugal Pump
}

\author{
Rouhollah Torabi and Seyyed Ahmad Nourbakhsh \\ Hydraulic Machinery Research Institute, School of Mechanical Engineering, College of Engineering, \\ University of Tehran, Tehran 1439955961, Iran \\ Correspondence should be addressed to Rouhollah Torabi; rtorabi@ut.ac.ir
}

Received 26 March 2016; Revised 21 May 2016; Accepted 29 May 2016

Academic Editor: Gerard Bois

Copyright ( 2016 R. Torabi and S. A. Nourbakhsh. This is an open access article distributed under the Creative Commons Attribution License, which permits unrestricted use, distribution, and reproduction in any medium, provided the original work is properly cited.

\begin{abstract}
Centrifugal pump delivery head and flow rate drop effectively during the pumping of viscous fluids. Several methods and correlations have been developed to predict reduction rate in centrifugal pump performance when handling viscous fluids, but their results are not in very good agreement with each other. In this study, a common industrial low specific speed pump, which is extensively used in different applications, is studied. The entire pump, including impeller, volute, pipes, front and rear sidewall gaps, and balance holes, is simulated in Computational Fluid Dynamics and 3D full Navier Stokes equations are solved. CFD results are compared with experimental data such as pump performance curves, static pressure in casing, and disk friction loss. Dimensionless angular velocity and leakage rate are investigated in sidewall gap and efficiency variation due to viscosity is studied. The results demonstrate that the behavior of the fluid in sidewall gap is strictly sensitive to viscosity. Increasing viscosity improves the volumetric efficiency by reducing internal leakage through wear rings and balance holes, causing, however, a significant fall in the disk and overall efficiency. Results lead to some recommendations for designing centrifugal pumps which may be used in transferring viscous fluids.
\end{abstract}

\section{Introduction}

Centrifugal pumps are usually capable of transferring liquids with viscosities lower than $520-760$ cSt. The viscosity can be increased to $1000 \mathrm{cSt}$ by using specific impellers. However, for a pump to be economically efficient, the maximum recommended liquid viscosity is $150 \mathrm{cSt}$ [1]. For a small industrial pump with $100 \mathrm{~mm}$ impeller radius and $1450 \mathrm{rpm}$ rotational speed, pumping liquid with $150 \mathrm{cSt}$ corresponds to impeller Reynolds number of $\mathrm{Re}=10^{4}$, while 520 and 760 cSt match $\mathrm{Re}=2900$ and 2000, respectively. Ippen [2] indicates that the expected efficiency, even for large pumps, for a Reynolds number of 5000 would be on the order of 30 percent.

Performance curves of centrifugal pumps which are presented in manufacturer documents are related to test with cold water. In addition, predicted performance of pumps for handling a viscous fluid is usually calculated by correction charts of some companies such as [3] and the viscosity diagram of Hydraulic Institute Standards [4]. In any pumping system, when water is substituted with a viscous fluid, the absorbed power increases while head and flow rate generated by the pump decrease. This phenomenon results from the reduction in the pump efficiency and is more evident in pumps with low specific speed in which viscosity plays a decisive role in disk friction loss. This kind of loss is the power absorbed for rotating the fluid between external surface of the impeller and internal wall of the casing. In this paper, a low specific centrifugal pump which was originally designed for water handling is investigated to analyze the influence of Reynolds number on efficiency due to pumping viscous fluid.

For a low specific speed centrifugal pump, some research on disk friction loss such as [5-7] was based on simplified model in which there is a rotating disk in a cylinder filled with viscous fluid, with or without radial inflow or outflow as shown in Figure 1. Littell and Eaton [8] measured turbulence characteristics of the boundary layer on an effectively infinite rotating disk in a quiescent environment. Debuchy et al. 


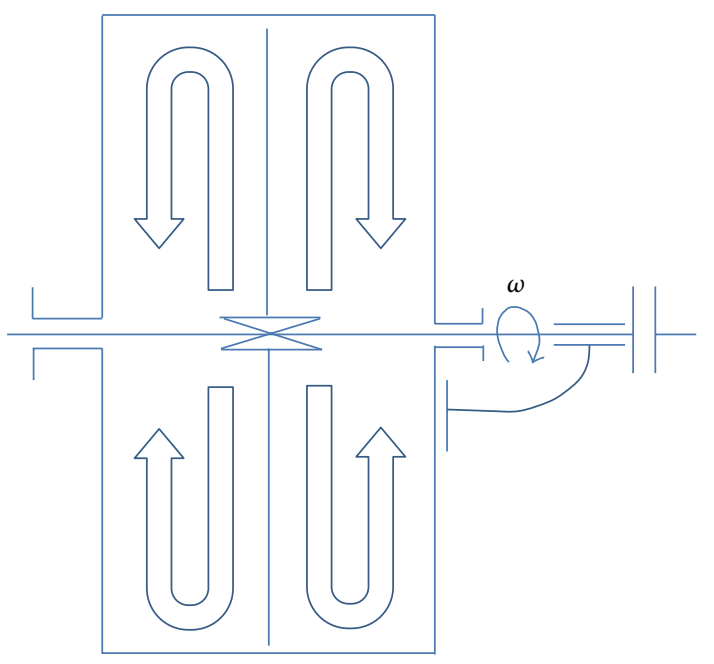

Figure 1: Simple model of disk friction loss.

$[9,10]$ presented new law relating the sidewall gap swirl ratio to the dimensionless flow coefficient in a rotor-stator system with superposed flow and, moreover, introducing an analytical modeling of the central core flow in a rotor-stator system with several preswirl conditions.

In recent years, some experimental and numerical investigations into viscosity effect on pump performance have been performed in real centrifugal pumps. Li [11-13] performed an experimental study on performance of centrifugal oil pump and studied numerically the effects of viscosity on centrifugal pump performance. Li [14] also investigated the effects of flow rate and viscosity on slip factor. He obtained the optimum number of blades for pumping liquid with different viscosity and showed some effects of viscosity on fluid regime inside the impeller and volute. Shojaeefard and Boyaghchi [15] accomplished CFD and experimental studies for viscosity effect on velocity in the impeller and indicated that when the blade outlet angle increases, the width of wake at the outlet of impeller decreases, leading to better pump performance in pumping viscous fluids. Nemdili and Hellmann [16] utilized a method to measure disk friction loss and tested disks without and with modified outlet sections with various numbers, angles, and widths. Gülich in 2003 [17] presented different correlations to estimate disk friction loss in closed turbomachine impellers. Juckelandt and Wurm [18] studied the effect of boundary layer on calculating losses in low specific speed pumps and presented some meshing guideline for these types of pumps.

\section{Theoretical Analysis}

The power consumption of a pump can be defined as

$$
P_{s}=\frac{\rho g Q H}{\eta_{v} \cdot \eta_{h}}+P_{d f}+P_{m}
$$

where $\rho$ is fluid density, $Q$ is pump flow rate, $H$ is pump delivery head, $\eta_{v}$ is volumetric efficiency, $\eta_{h}$ is hydraulic efficiency, $P_{d f}$ is disk friction loss, and $P_{m}$ is mechanical loss.
By increasing the viscosity the power balance will change in the following way:

(i) With growing the friction factor, the internal leakage through wear rings decreases.

(ii) With increasing Reynolds number, hydraulic efficiency increases.

(iii) Disk friction losses on the impeller sidewalls grow along with the increasing viscosity.

(iv) The mechanical losses are independent of the viscosity of the fluid.

2.1. Disk Friction Loss. The wall shear stress occurring on surfaces of a rotating disk in a casing full of fluid can be written as follows:

$$
\tau=\frac{\rho c_{f} r^{2} \omega^{2}}{2}
$$

where $c_{f}$ is friction coefficient, $r$ is radius, and $\omega$ is angular velocity of disk. The resultant torque applied to a surface element is

$$
d M=r \times d F=r \times \tau d A=\pi \rho c_{f} r^{4} \omega^{2} d r .
$$

The friction power of the disk will be

$$
P_{d f}=\omega \times \int_{r_{1}}^{r_{2}} d M=\frac{\pi \rho c_{f} R^{5} \omega^{3}}{5} \cdot\left(1-\frac{r_{1}{ }^{5}}{R^{5}}\right),
$$

where $R$ is impeller outer radius.

2.2. Hydraulic Effect. Theoretical head of a centrifugal pump is the sum of the useful head, $H_{w}$, and the hydraulic losses. It can be demonstrated that the theoretical head, $H_{\mathrm{th}}$, is essentially the same when a pump operates with water (subscript $w$ ) or with viscous fluid (subscript $v$ ). Hydraulic losses are considered to consist of friction losses, $Z_{R}$, and mixing losses, $Z_{M}$ [19]:

$$
H_{\mathrm{th}}=H_{w}+Z_{R, w}+Z_{M, w}=H_{v}+Z_{R, v}+Z_{M, v} .
$$

Friction loss is the term that changes with viscosity; hence, the head correction factor in viscous pumping can be calculated through the following formula [19]:

$$
f_{H}=\frac{H_{v}}{H_{w}}=\frac{\eta_{h, v}}{\eta_{h, w}}=1-\alpha\left(\frac{C_{f, v}}{C_{f, w}}-1\right),
$$

where $\alpha$ is the fraction of friction losses to the head and can be defined mostly on geometric features. The correlation which can be used to calculate this fraction for a wide range of specific speed is [19]

$$
\alpha=\frac{Z_{R, w}}{H_{w}}=0.058+0.09\left(\frac{n_{s}-30}{30}\right)^{2} .
$$

More detailed procedure to calculate $C_{f}$ and $f_{H}$ can be found in $[17,19]$. 
TABLE 1: Main dimensions of the investigated pump.

\begin{tabular}{lc}
\hline Impeller rated diameter $(\mathrm{mm})$ & 200 \\
Impeller full diameter $(\mathrm{mm})$ & 209 \\
Impeller outlet width, $b_{2}(\mathrm{~mm})$ & 4.2 \\
Blade outlet angle, $\beta_{2}(\mathrm{deg})$ & 20 \\
Number of blades & 6 \\
Number of balance holes & 6 \\
Shroud thickness at impeller tip $(\mathrm{mm})$ & 3.7 \\
Volute base circle diameter $(\mathrm{mm})$ & 210 \\
Suction nozzle diameter $(\mathrm{mm})$ & 50 \\
Discharge nozzle diameter $(\mathrm{mm})$ & 40 \\
Impeller suction eye diameter $(\mathrm{mm})$ & 61 \\
Wear ring radial clearance $(\mathrm{mm})$ & 0.4 \\
Diameter of balance holes $(\mathrm{mm})$ & 7 \\
Hub thickness at impeller tip $(\mathrm{mm})$ & 4.1 \\
\hline
\end{tabular}

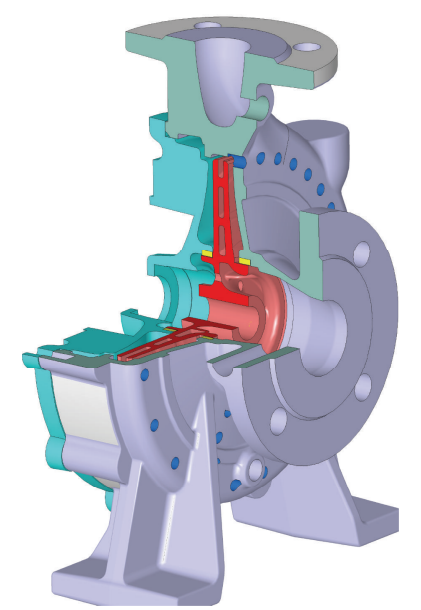

FIGURE 2: Cutaway drawing of the pump parts.

\section{Geometry of the Pump}

The investigated pump (Figure 2) is a single-stage, endsuction volute pump with a specific speed of $n_{s}=10.3$ at BEP of full diameter impeller and $n_{s}=12.8$ at rated impeller. The pump is a back pull-out construction with a six-blade closed impeller and six balance holes so as to reduce the axial thrust. At the design point, the hydraulic specifications of the pump at best efficiency point of rated impeller are $Q=9 \mathrm{~m}^{3} / \mathrm{h}$, $H=10.1 \mathrm{~m}, \eta=46 \%, N=1450 \mathrm{rpm}$, and $P=0.55 \mathrm{~kW}$ and impeller Reynolds number for pumping water is $\mathrm{Re}=1.5$ $\times 10^{6}$. More detailed dimensions can be found in Table 1 .

\section{Numerical Simulation}

The commercial CFD code ANSYS CFX was employed for the numerical simulation of the pump fluid domain (Figure 3) which utilizes a cell-centered control volume with identical nodes for velocity and pressure. A blending factor is computed locally, which is used for the spatial discretization method of the convective terms implemented with a hybrid scheme. The flow was assumed to be at steady state and incompressible and isothermal. Turbulence effects were modeled, using the $k$ - $\omega$ SST procedure with adiabatic wall boundary conditions. This turbulent method, according to several scholars $[17,20]$, is considered as the best choice for modeling of flow in centrifugal pumps since it has shown a good compromise between accuracy and computational effort even for the region of impeller sidewall gap [21]. Results of similar research such as $[15,18]$ demonstrate satisfactory results with $k-\omega$ SST model. Moreover, in order to model transition, we benefited the Langtry and Menter correlation and the "Gamma Theta Model" in this simulation.

To achieve an improved mesh quality, for the regions which are located near walls, the structured mesh was used, whereas unstructured mesh was employed for areas away from the wall to properly cover the complex geometry (Figure 4). Therefore, a better conformity between the mesh domain and the complicated geometry has been obtained. The unstructured mesh constitutes six-sided pyramid and wedge-shaped elements.

Orthogonal quality, aspect ratio, and skewness were inspected during the grid generation process, to be in appropriate range. The grids between rotating and stationary parts such as impeller and volute or suction pipe and impeller were adjoined by means of frozen rotor interface. Mass flow rate with flow direction and constant pressure were implemented for inlet and outlet boundary conditions, respectively.

\section{Experimental Setup}

A closed loop test rig fulfilling the requirements of ISO 9906 [22] was used in order to measure the experimental parameters of the pump. Figure 5 presents a schematic view of the test setup in which the fluid is drawn from the tank (1) with $2.1 \mathrm{~m}^{3}$ net volume and after passing through a gate valve (2) and suction pipe ( $1.5 \mathrm{~m}$ length and $40 \mathrm{~mm}$ inside diameter) it enters the investigated pump (4) and then returns the tank through the discharge pipe ( $4 \mathrm{~m}$ length and $50 \mathrm{~mm}$ inside diameter). There is a Transverse baffle inside the tank to reduce liquid slosh and ensure the fluid streams into the suction pipe smoothly. The pump is coupled to an AC electric motor (5) whose rated power and speed are $3 \mathrm{~kW}$ and $1450 \mathrm{rpm}$, respectively. Pump head is calculated by using pressure transducers with accuracy of $0.25 \%$ of the full scale in (3) and (7). The flow rate is adjusted by means of a globe valve (8) located in discharge line of the pump. Steady state flow rate is measured by a magnetic flow meter (9) with the accuracy of $0.5 \%$. To calculate power, the torque and speed of the motor are measured via a torque meter (6) and tachometer, whose accuracies are $0.3 \%$ and $0.1 \%$ respectively.

To determine the pressure field in the sidewall gap and validate numerical results, peripheral distribution of static pressure is measured by means of pressure transducer with accuracy of $0.25 \%$ of the full scale. The signals from the transducers are digitalized by a data acquisition device and, with capturing enough samples, the data are averaged arithmetically. The uncertainties of flow rate, head, power, 

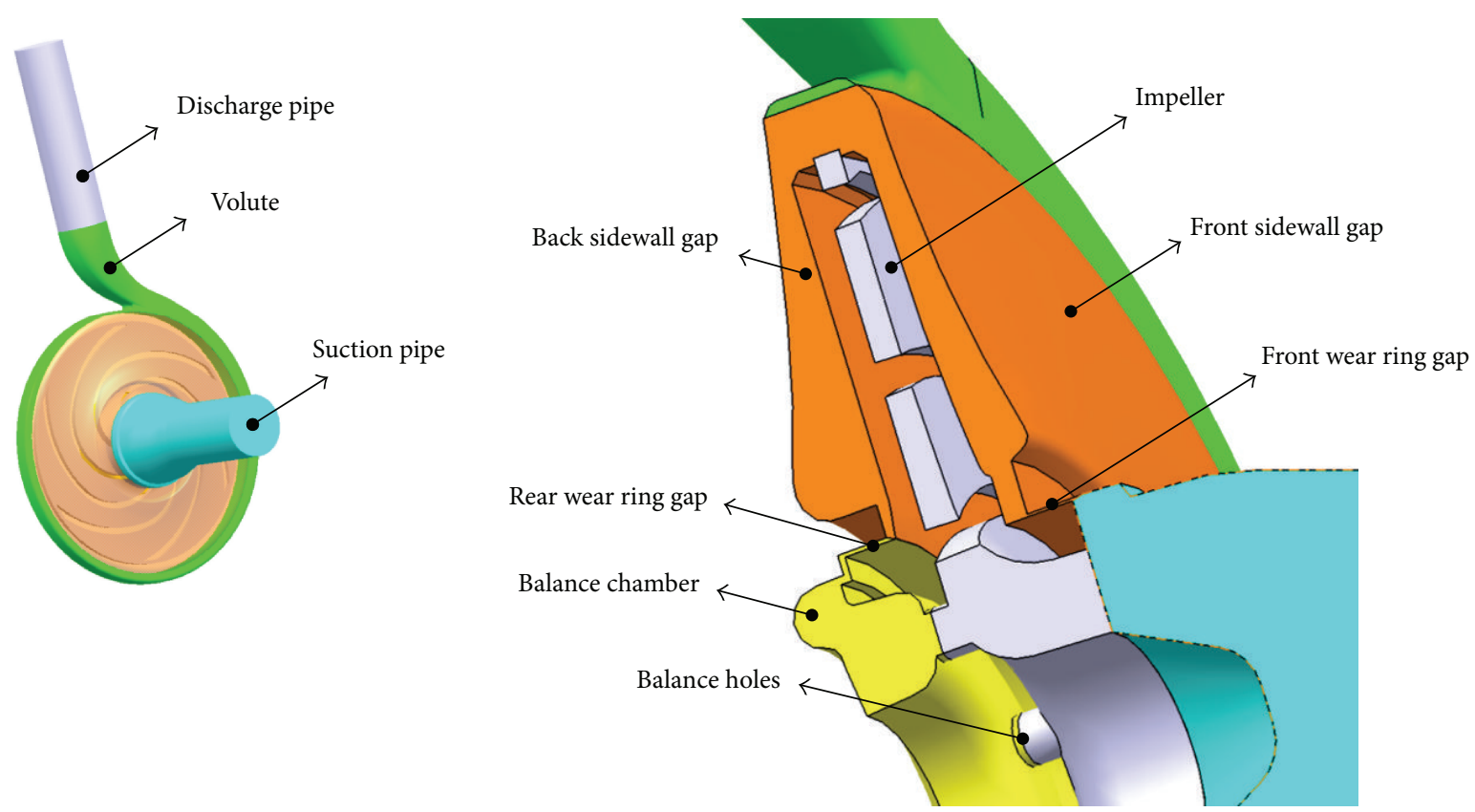

Figure 3: CFD model of the pump (fluid domain).
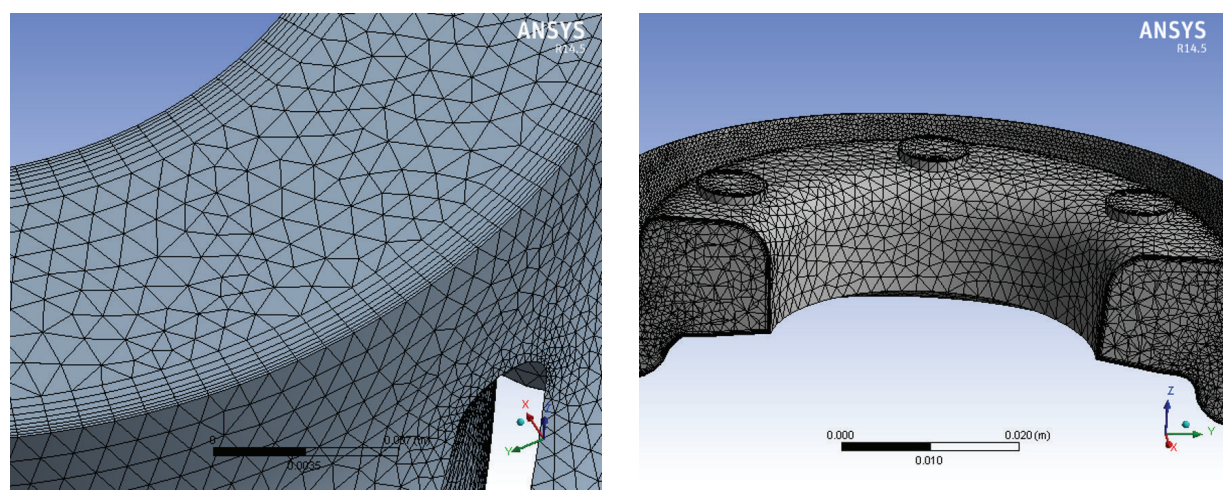

FIGURE 4: Mesh configuration used for flow analysis.

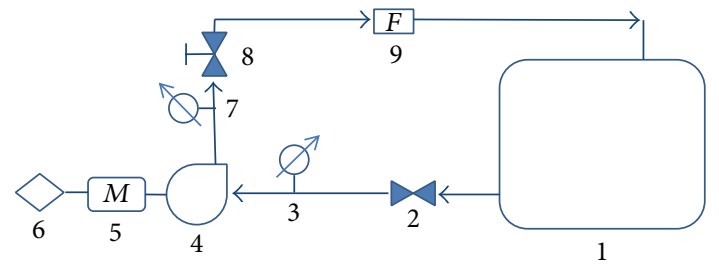

Figure 5: Centrifugal pump test setup.

and efficiency are approximately $0.5 \%, 0.3 \%, 0.5 \%$, and $1 \%$, respectively.

\section{Results and Discussion}

To validate the CFD simulation, in Table 2 , at BEP condition, the results of dimensionless steady state, static pressure, and $p^{*}=p / \rho \omega^{2} R^{2}$ distribution on the casing wall, around the impeller at $r=107 \mathrm{~mm}$ for water are shown. The volute is divided into 6 sectors in which there are four holes in the casing wall of each sector. The static pressure was measured in each point and then averaged in each sector. CFD results were also averaged in each sector and are compared to relevant measurements. Volute tongue is located at $\theta=77^{\circ}$ in which the pressure fluctuation is greater than the other locations. Experimental data and CFD results are in agreement and the averaged error is about $2 \%$. Results of pumping oil with $v=90 \mathrm{cSt}$ are also in the same range of error.

Figure 6 presents the comparison between CFD results and experimental data including dimensionless head, $\psi=$ $g H / \omega^{2} R^{2}$, and efficiency versus dimensionless flow rate, $\varphi=$ $Q / \omega b_{2} R^{2}$, where $b_{2}$ is impeller outlet width and $R$ is impeller outer radius. As it is shown there is a good agreement between CFD and experimental data even in part load and overload regions. The BEP is located in $\varphi=0.39$ with the head of $\psi=0.43$. 


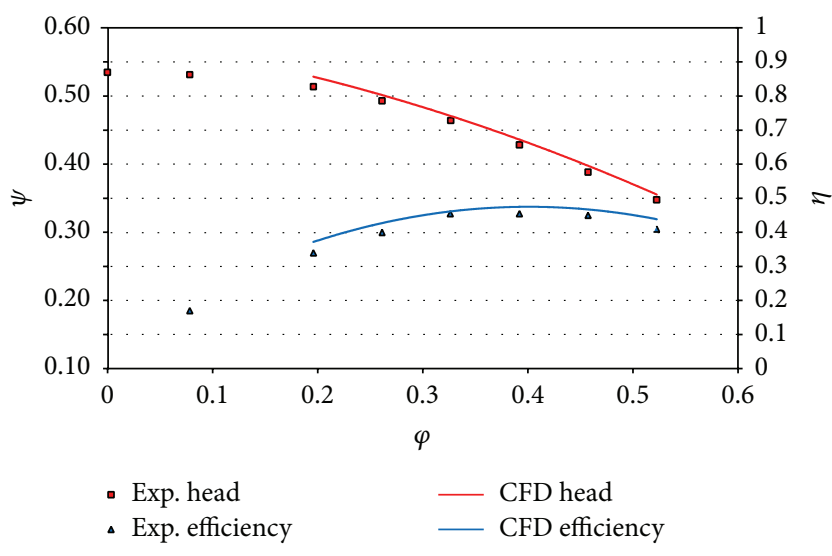

Figure 6: Comparison of CFD and test results for water.

TABLE 2: Results of averaged static pressure $p^{*}$ on casing wall at BEP in six sectors around the impeller $(r=107 \mathrm{~mm})$.

\begin{tabular}{lccc}
\hline Sector & CFD & Exp. & Error\% \\
\hline 1 & 0.390 & 0.379 & $2.9 \%$ \\
2 & 0.409 & 0.397 & $3.0 \%$ \\
3 & 0.403 & 0.403 & $0 \%$ \\
4 & 0.407 & 0.404 & $0.7 \%$ \\
5 & 0.408 & 0.400 & $1.9 \%$ \\
6 & 0.405 & 0.393 & $2.9 \%$ \\
\hline
\end{tabular}

Pump performance curve for oil with $v=90 \mathrm{cSt}(\mathrm{Re}=$ $17 \times 10^{3}$ ) resulting from different method is plotted in Figure 7. The analytic curve is based on calculating the $H_{v}$ based on value of $f_{H}$ from (6) and as it is shown the analytic method is not close to experiments in this matter and may be used for estimation or finding the trend of changing.

The graph published in [3] to calculate the influence of viscosity introduces the procedure yielding the correction factors $\left(f_{\mathrm{Q}}\right.$ and $\left.f_{H}\right)$ as a function of flow rate, head, kinematic viscosity, rotational speed, and also the significant influence of the specific speed, $n_{s}$. This method is based on measurements with $n_{s}$ from 6.5 to 45 and viscosity even up to $4000 \mathrm{cSt}$. Since this method does not take into account the influence of the ratio of the actual flow rate to the flow at the BEP $\left(q^{*}\right)$, the results in low flow rate are different from experimental data; however, near BEP it shows accurate results. Thus, this method seems to overpredict the amount of losses for viscous oils and therefore is more cautious method.

CFD curve is obtained from simulating flow in 6 operating points and as it is shown the agreement between the CFD results and experimental data is acceptable especially in lower flow rates. The largest error as expected has occurred in overload condition which is less than $10 \%$ in $\varphi=0.42$.

It has been shown in Figure 7 that in low flow rate the effect of viscosity on pump head is smaller than in higher flow rate; therefore, shut-off head of pump with viscous liquid does not differ much from that with water. In this point of view, part load is more preferable than overload in pump selection procedure for delivering viscous fluids. The designer may choose a larger pump, so the operating point will locate

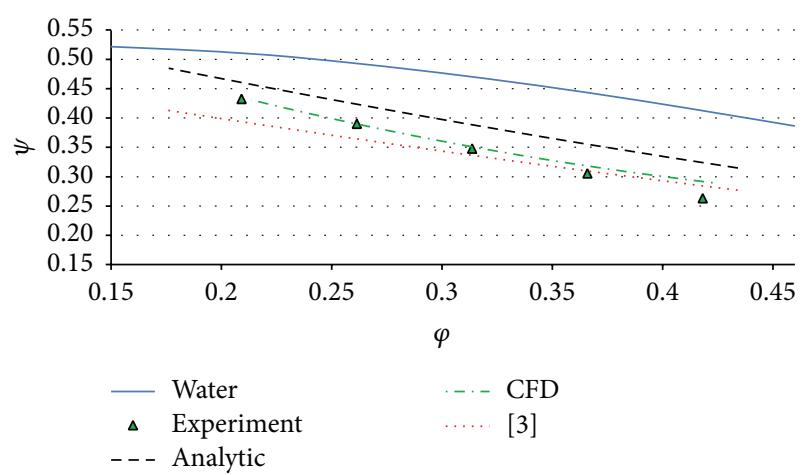

FIGURE 7: Comparison of resultant $\psi-\varphi$ curve from different methods $(\nu=90 \mathrm{cSt})$.

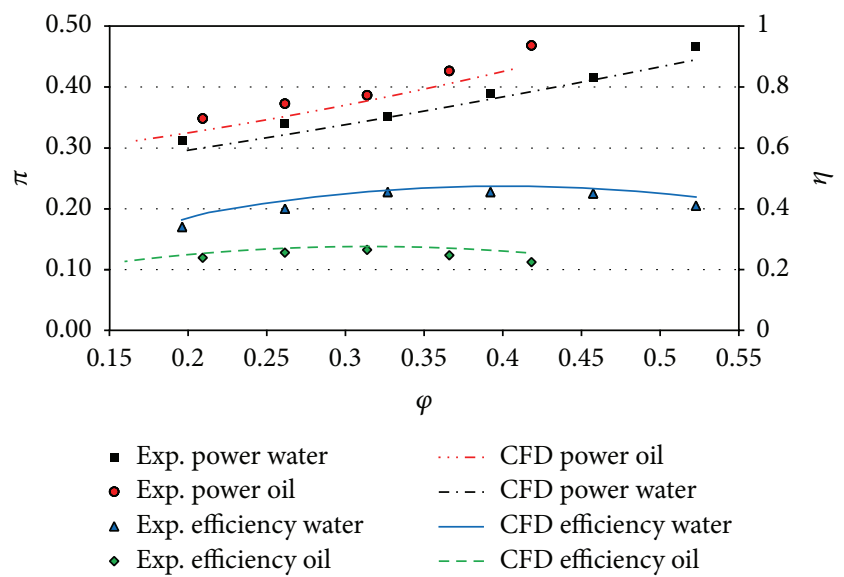

FIGURE 8: Influence of viscosity on efficiency and shaft power.

TABLE 3: Effect of operating point location on reduction of pump head for three viscous fluids: $a=35 \mathrm{cSt}\left(\mathrm{Re}=43 \times 10^{3}\right), b=64 \mathrm{cSt}$ $\left(\operatorname{Re}=24 \times 10^{3}\right)$, and $c=90 \mathrm{cSt}\left(\operatorname{Re}=17 \times 10^{3}\right)$.

\begin{tabular}{lccc}
\hline$\varphi^{*}$ & $\Delta \psi^{*}(a)$ & $\Delta \psi^{*}(b)$ & $\Delta \psi^{*}(c)$ \\
\hline 0.5 & 0.07 & 0.12 & 0.14 \\
0.65 & 0.11 & 0.17 & 0.20 \\
0.8 & 0.12 & 0.20 & 0.26 \\
1.1 & 0.2 & 0.32 & 0.38 \\
\hline
\end{tabular}

in the left side of BEP and thus the effect of viscosity on pump performance will decrease. Table 3 demonstrates the influence of operating point location, at 3 constant absolute flow rate $\left(\varphi^{*}=\varphi / \varphi_{\mathrm{BEP}, w}\right)$ on head reduction $\left(\Delta \psi^{*}=\left(\psi_{w}-\right.\right.$ $\left.\psi_{v}\right) / \psi_{w}$ ) based on experimental data.

Figure 8 illustrates the efficiency and absorbed power curve for water and viscous fluid with $v=90 \mathrm{cSt}$ ( $\mathrm{Re}=$ $17 \times 10^{3}$ ) and $\rho=880 \mathrm{~kg} / \mathrm{m}^{3}$. Based on experimental results, correction factor for flow rate in BEP which is equal to the shift in BEP location due to viscosity is about $f_{\mathrm{Q}}=0.8$ and efficiency drop in this point is near $f_{\eta}=0.58$, while Figure 7 shows that the head coefficient reduction compared to water curve is approximately $f_{H}=0.82$. Since the head and flow rate are reduced and the density of the oil is $88 \%$ of the 


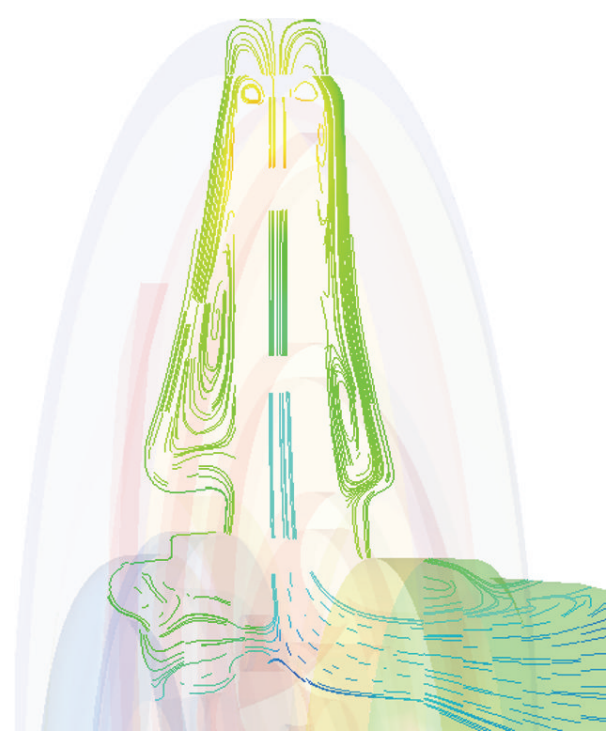

FIGURE 9: Streamline of flow inside pump.

water, the absorbed powers of these two points are near each other. CFD and experimental values are quite in agreement in BEP while in off design conditions the error has increased as expected.

Figure 9 shows streamline of flow including front and rear leakage through wear rings. Internal leakage towards impeller eye usually affects primary flow of impeller suction. Rate of leakage in front and rear wear rings does not differ much since balance holes are large enough and resultant friction resistance is negligible compared to wear rings. Forming vortex flow in sidewall gap depends upon several parameters such as angular momentum of entering flow, geometry of the core, and Reynolds number.

Figure 10 illustrates the velocity vector of leakage flow through front wear rings. Leakage flow to impeller suction eye forms a vortex zone in this region, which affects the uniform regime of fluid entering the impeller. As shown in Figure 10, this zone has a larger area when the pump is used for pumping low viscous fluid such as water.

The dimensionless internal leakage rate $\left(\varphi_{G}\right)$ through front wear rings is demonstrated in Figure 11. By increasing viscosity from 1 to $90 \mathrm{cSt}$, leakage rate reduced by more than $80 \%$. Another way to limit internal leakage is to restrict wear ring clearance in order to raise volumetric efficiency.

When the pump is utilized for pumping viscous fluids, use of impeller back vanes or expeller to balance axial thrust is not recommended due to increase in disk friction loss. The best way is to use balance holes and mating wear rings even with a larger clearance in order to minimize repair intervals and extend the operating life of rings. This geometrical optimization diminishes the risk of face contact of wear rings due to shaft deflection or misalignment and thus improves reliability of the equipment which is completely important in specific applications. API 610 Standard [23] has listed the minimum allowable running clearance of wear rings for centrifugal pumps used in petroleum, oil, and gas industries which is $0.15 \mathrm{~mm}$ radial clearance for this pump. The dash line in Figure 11 demonstrates minimum leakage rate corresponding to this clearance. Although this modification effectively restricts the leakage, the volumetric efficiency hardly can reach $90 \%$ if the medium is water or any other thin liquid. To compensate for the significant negative effect of wide gap on volumetric efficiency, wear rings with a larger length or labyrinth shape and small balance holes could be used. Admittedly, the balance hole numbers and diameter should be enough to ensure that the axial thrust is controlled satisfactorily.

The circumferential velocity of fluid in sidewall gap is normally described by the dimensionless angular velocity $K$, defined as the ratio of the angular velocity of the fluid to the angular velocity of the impeller. Figure 12 illustrates $K$ along the radius in the sidewall gap.

When centrifugal pump handles water instead of oil, Reynolds number and leakage flow rate through rings $\left(\varphi_{G}\right)$ increase, while both of them are major parameters that affect $K$. In case of water, dimensionless local angular velocity rises towards the inner radius up to 0.9, whereas for oil (90 cSt) it is less than 0.6. Similar measurement has been taken by Schubert [24] which demonstrates the influence of the leakage flow and Reynolds number on angular velocity. Test result of Hergt and Prager [25] for a centrifugal pump with leakage rate of $\varphi_{G}=0.0008$ is reported in Figure 12 which shows good agreement with water curve.

Figure 13 compares the influence of decreasing Reynolds number by means of viscous fluid on pump efficiencies at BEP which includes positive effect on volumetric efficiency and negative effect on disk friction and hydraulic efficiencies. According to results of CFD, in case of pumping water ( $\mathrm{Re}$ $=1.5 \times 10^{6}$ ), volumetric efficiency is about $75 \%$, hydraulic efficiency is $77 \%$, and disk friction efficiency is near $84 \%$ and thus overall efficiency is about $47 \%$. By decreasing the Reynolds number to $\operatorname{Re}=17 \times 10^{3}$ in case of pumping oil with $90 \mathrm{cSt}$ viscosity, values change significantly. The volumetric efficiency improves around $20 \%$ whereas the hydraulic efficiency reduces by $14 \%$ and disk friction efficiency drops by $38 \%$ and accordingly the overall efficiency reduces approximately by $21 \%$.

If pumping highly viscous liquid ( $v>90 \mathrm{cSt}$ ) with this pump is intended, it seems that, in Reynolds number smaller than 15000, volumetric efficiency cannot be improved noticeably, while disk friction efficiency will continue to drop dramatically and accordingly the total efficiency will degrade more.

The amount of efficiency data versus oil viscosity is summarized in Table 4. Enhancing the volumetric efficiency is more significant in lower viscosities. For example, when the viscosity increases from 1 to $35 \mathrm{cSt}$, the volumetric efficiency grows by $14 \%$; however, it grows by just $5 \%$ from 35 to $90 \mathrm{cSt}$. A similar dependency takes place for disk friction efficiency but the rate of reduction is larger in both ranges, that is, $26 \%$ drop for viscosity from 1 to $35 \mathrm{cSt}$ and $13 \%$ for 35 to 90 cSt. Furthermore, CFD results show that, in case of pumping water, the ratio of disk friction power to shaft power is about $15 \%$, but when the viscosity of fluid is $90 \mathrm{cSt}$, this 


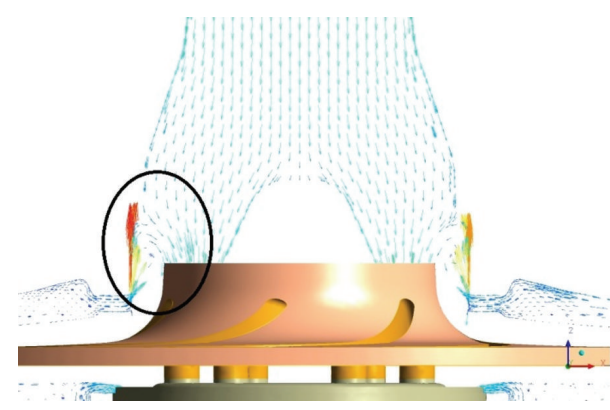

(a)

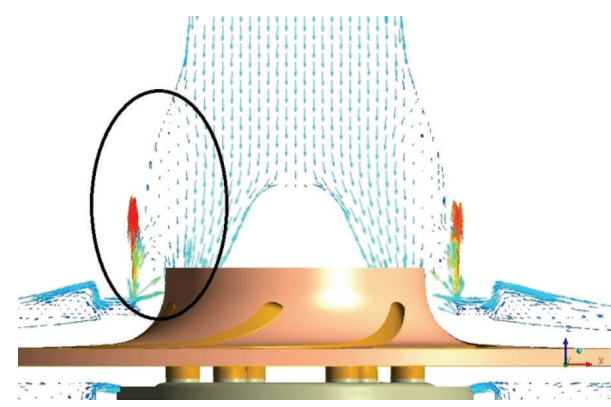

(b)

FIGURE 10: Influence of leakage flow on impeller suction regime. Right: water; left: viscous fluid.

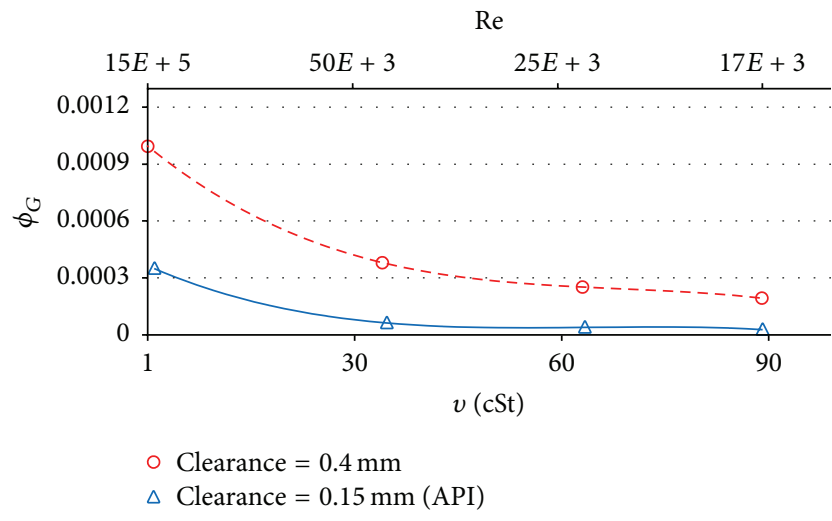

FIGURE 11: Leakage rate through front wear rings versus viscosity and Reynolds number.

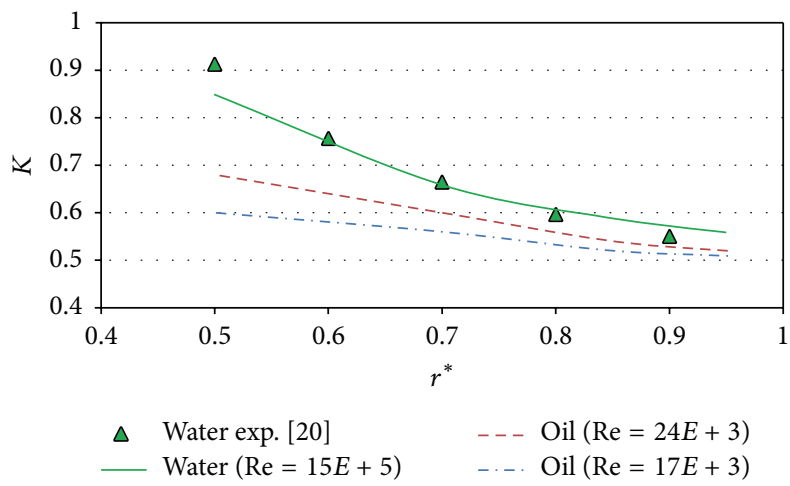

FIGURE 12: Effect of Reynolds number on dimensionless fluid rotational angular velocity.

ratio intensely grows up to more than 50\%. Consequently, when the viscosity increases, although hydraulic losses due to friction and turbulent dissipation in all components increase, the main reason for degrading the efficiency is disk friction loss which occurs in sidewall gaps.

\section{Conclusions}

In this paper, the effects of decreasing Reynolds number due to change in viscosity on centrifugal pump performance were

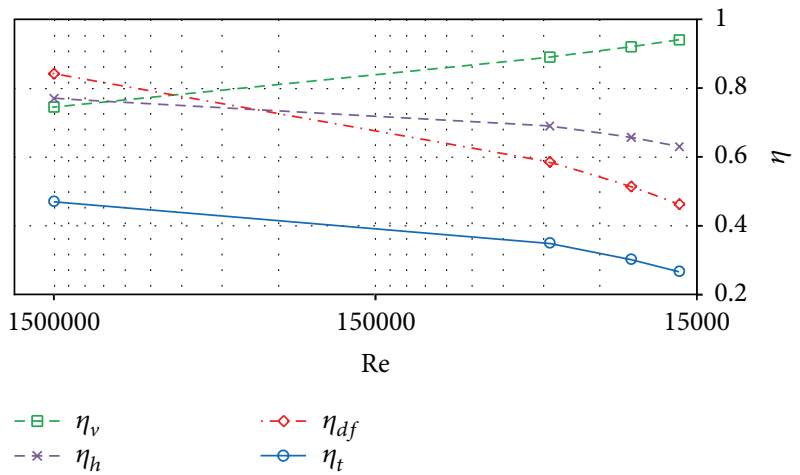

FIGURE 13: Efficiency as a function of Reynolds number, based on CFD results.

TABLE 4: The effect of oil viscosity on pump efficiency, based on CFD results.

\begin{tabular}{lcccc}
\hline & $1 \mathrm{cSt}$ & $35 \mathrm{cSt}$ & $64 \mathrm{cSt}$ & $90 \mathrm{cSt}$ \\
\hline$\eta_{v}$ & 0.75 & 0.89 & 0.92 & 0.94 \\
$\eta_{h}$ & 0.77 & 0.69 & 0.66 & 0.63 \\
$\eta_{d f}$ & 0.84 & 0.58 & 0.50 & 0.45 \\
$\eta_{m}$ & 0.98 & 0.98 & 0.98 & 0.98 \\
$\eta_{t}$ & 0.47 & 0.35 & 0.30 & 0.26 \\
\hline
\end{tabular}

studied for a low specific speed pump. The results of CFD agreed well with experimental data in BEP region; however, in overload conditions, the accuracy of CFD was limited. Considering the experimental and numerical investigations, the following conclusions can be made:

(i) In part-load region, the effect of viscosity on pump performance is smaller than that in BEP and overload regions. For $90 \mathrm{cSt}$ oil, head coefficient reduces by just $14 \%$ in constant flow rate of $0.5 Q_{\mathrm{BEP}, w}$ while for $1.1 Q_{\mathrm{BEP}, w}$ it drops by approximately $38 \%$.

(ii) With decreasing the Reynolds number, the leaked flow through wear rings and balance holes decreases and thus the volumetric efficiency increases remarkably. For wear rings with $0.4 \mathrm{~mm}$ clearance, the volumetric efficiency improves by approximately $20 \%$ 
if the impeller Reynolds number reduces to $17 \times 10^{3}$ from $1.5 \times 10^{6}$.

(iii) The dimensionless rotational angular velocity in the sidewall gap drops effectively by decreasing the Reynolds number resulting in greater drag on impeller. $10 \%$ and $30 \%$ reduction occurs in outer and inner radii, respectively, when decreasing viscosity from $1.5 \times 10^{6}$ to $17 \times 10^{3}$.

(iv) Disk friction power increases from $15 \%$ of total shaft power to more than $50 \%$ when water is replaced with 90 cst fluid. Therefore, although volumetric efficiency improves, the overall efficiency of pump decreased by $21 \%$.

(v) In case of pumping oils, use of expeller for limiting thrust load and very tight wear ring clearance for improving volumetric efficiency should be avoided. Impeller balance holes with optimum rear and front ring clearance may be utilized to prevent undesirable hydraulic and mechanical effects.

\section{Nomenclature}

$b_{2}$ : Impeller outlet width

$C_{f}$ : Friction coefficient

$D$ : Impeller outlet diameter

$f_{H}$ : Viscosity correction factor for head

$f_{\mathrm{Q}}$ : Viscosity correction factor for flow rate

$f_{\eta}$ : Viscosity correction factor for efficiency

$H$ : Delivery head

$K: \quad$ Rotation of fluid in impeller sidewall gap $=\beta / \omega$

$n_{s}:$ Pump specific speed

$p:$ Pressure

$p^{*}:$ Dimensionless pressure $=p / \rho \omega^{2} R^{2}$

$P_{d f}$ : Disk friction power

$P_{s}$ : Shaft power

$P_{m}:$ Mechanical power

$P_{h}$ : Useful hydraulic power

Q: Volume flow rate

$R:$ Impeller outer radius

$r$ : Radius

$R^{*}:$ Dimensionless radius $=r / R$

Re: Reynolds number $=\omega R^{2} / v$

$Z_{R}$ : Hydraulic friction losses

$Z_{M}$ : Hydraulic mixing losses

$\varphi_{G}:$ Dimensionless leak flow $=Q / \pi \omega R^{3}$

$\alpha$ : Fraction of friction losses to the head

$\beta$ : Angular velocity of the fluid

$v$ : Kinematic viscosity

$\rho: \quad$ Fluid density

$\psi: \quad$ Head coefficient $=g H / \omega^{2} R^{2}$

$\varphi: \quad$ Flow coefficient $=Q / \omega b_{2} R^{2}$

$\pi: \quad$ Power coefficient $=P / \omega^{3} b_{2} R^{4}$

$\eta_{t}:$ Pump overall efficiency

$\eta_{v}$ : Pump volumetric efficiency

$\eta_{h}$ : Pump hydraulic efficiency

$\eta_{m}$ : Pump mechanical efficiency

$\eta_{d f}:$ Pump disk friction efficiency.

\section{Subscripts}

$v$ : Viscous fluid

$w$ : Water

th: Theoretical

BEP: Best efficiency point of pump.

\section{Competing Interests}

The authors declare that they have no competing interests.

\section{References}

[1] A. Nourbakhsh, A. Jaumotte, C. Hirsch, and H. B. Parizi, Turbopumps and Pumping Systems, Springer, Berlin, Germany, 2008.

[2] A. T. Ippen, "The influence of viscosity on centrifugal pump performance," Transactions of the American Society of Mechanical Engineers, vol. 68, no. 8, pp. 823-848, 1946.

[3] K. Holzenberger and K. Jung, KSB Centrifugal Pump Lexicon, KSB Aktiengesellschaft, 1990.

[4] "Effect of liquid viscosity on pump performance," ANSI/HI Standard 9.6.7-2004, 2004.

[5] B. Hudimoto and K. Hirose, "Frictional resistance of a rotating disc," Transactions of the Japan Society of Mechanical Engineers, vol. 17, no. 56, pp. 92-95, 1951.

[6] K. Watabe, "On fluid resistance of enclosed rotating rough discs," Bulletin of JSME, vol. 8, no. 32, pp. 609-619, 1965.

[7] J. M. Owen and J. R. Pincombe, "Velocity measurements inside a rotating cylindrical cavity with a radial outflow of fluid," Journal of Fluid Mechanics, vol. 99, no. 1, pp. 111-127, 1980.

[8] H. S. Littell and J. K. Eaton, "Turbulence characteristics of the boundary layer on a rotating disk," Journal of Fluid Mechanics, vol. 266, pp. 175-207, 1994.

[9] R. Debuchy, F. Abdel Nour, and G. Bois, "On the flow behavior in rotor-stator system with superposed flow," International Journal of Rotating Machinery, vol. 2008, Article ID 719510, 10 pages, 2008.

[10] R. Debuchy, F. A. Nour, and G. Bois, "An analytical modeling of the central core flow in a rotor-stator system with several preswirl conditions," Journal of Fluids Engineering, vol. 132, no. 6, 2010.

[11] W. G. Li and Z. M. Hu, "An experimental study on performance of centrifugal oil pump," Fluids Machinery, vol. 25, no. 2, pp. 3-7, 1997.

[12] W.-G. Li, "Effects of viscosity of fluids on centrifugal pump performance and flow pattern in the impeller," International Journal of Heat and Fluid Flow, vol. 21, no. 2, pp. 207-212, 2000.

[13] W.-G. Li, "Numerical study on behavior of a centrifugal pump when delivering viscous oils-part 1: performance," International Journal of Turbo and Jet Engines, vol. 25, no. 2, pp. 61-79, 2008.

[14] W.-G. Li, "Effects of flow rate and viscosity on slip factor of centrifugal pump handling viscous oils," International Journal of Rotating Machinery, vol. 2013, Article ID 317473, 12 pages, 2013.

[15] M. H. Shojaeefard and F. A. Boyaghchi, "Studies on the influence of various blade outlet angles in a centrifugal pump when handling viscous fluids," American Journal of Applied Sciences, vol. 4, no. 9, pp. 718-724, 2007. 
[16] A. Nemdili and D. H. Hellmann, "Investigations on fluid friction of rotational disks with and without modified outlet sections in real centrifugal pump casings," Forschung im Ingenieurwesen, vol. 71, no. 1, pp. 59-67, 2007.

[17] J. F. Gülich, Centrifugal Pumps, Springer, Berlin, Germany, 2014.

[18] K. Juckelandt and F.-H. Wurm, "Applicability of wall-function approach in simulations of turbomachines," in Proceedings of ASME Turbo Expo 2015: Turbine Technical Conference and Exposition (GT '15), June 2015.

[19] J. F. Gülich, "Pumping highly viscous fluids with centrifugal pumps-part 1," World Pumps, vol. 1999, no. 395, pp. 30-34, 1999.

[20] Y. Wang and W. J. Wang, "Applicability of eddy viscosity turbulence models in low specific speed centrifugal pump," IOP Conference Series: Earth and Environmental Science, vol. 15, no. 6, Article ID 062013, 2012.

[21] S. Poncet, R. Da Soghe, and B. Facchini, "RANS modeling of flows in rotating disk systems," in Proceedings of the 5th European Conference on Computational Fluid Dynamics (ECCOMAS CFD '10), Lisbon, Portugal, June 2010.

[22] ISO, "Rotordynamic pumps: hydraulic performance acceptance tests-grades 1 and 2," ISO 9906, 2000.

[23] API, Centrifugal Pumps for Petroleum Heavy Duty Chemical and Gas Industry Services, API Standard 610, 11th edition, 2009.

[24] F. Schubert, Untersuchungen der druck- und geschwindigkeitsverteilung in radseitenräumen radialer strömungsmaschinen [Ph.D. dissertation], TU Braunschweig, Braunschweig, Germany, 1988.

[25] P. Hergt and S. Prager, "Influence of different parameters on the disc friction losses of a centrifugal pump," in Proceedings of the Hydraulic Machinery, pp. 172-179, Budapest, Hungary, 1991. 


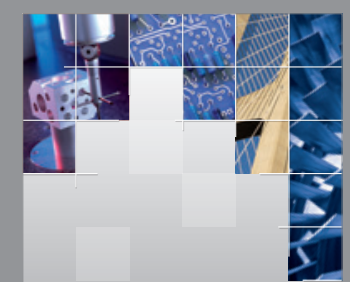

\section{Enfincering}
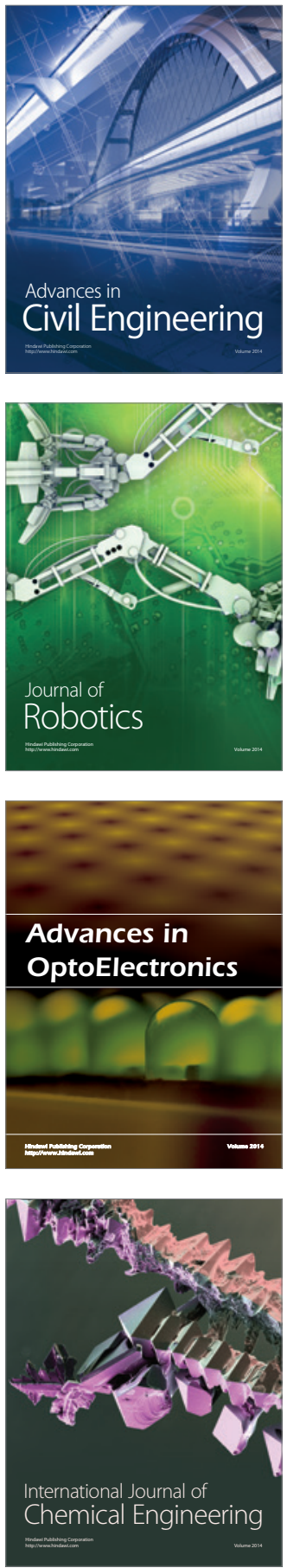

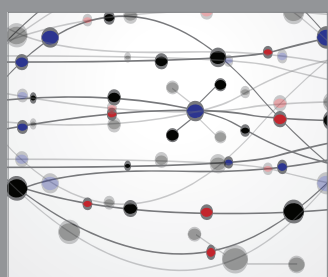

The Scientific World Journal

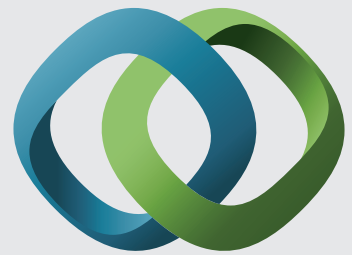

\section{Hindawi}

Submit your manuscripts at

http://www.hindawi.com
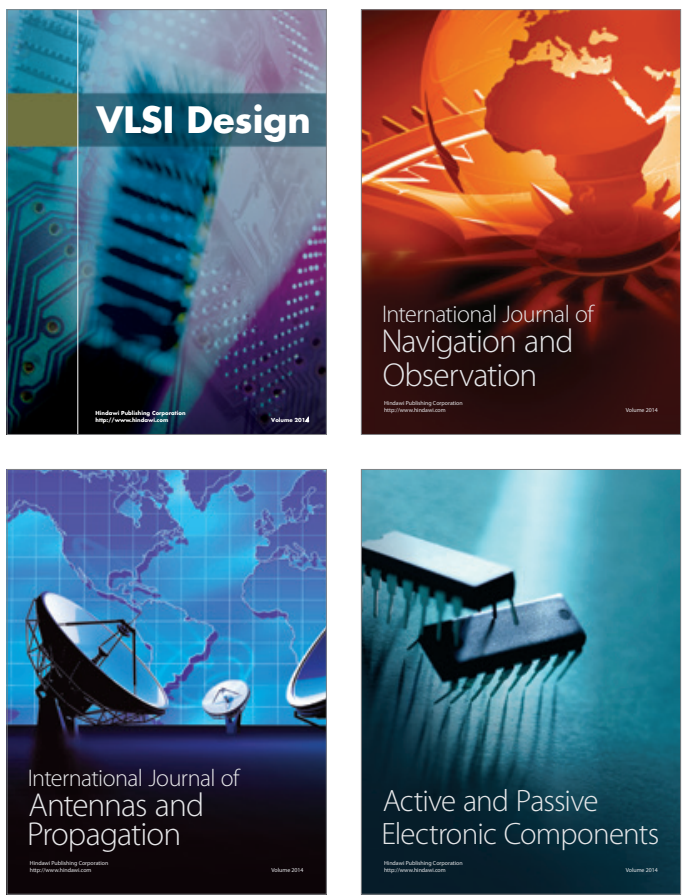
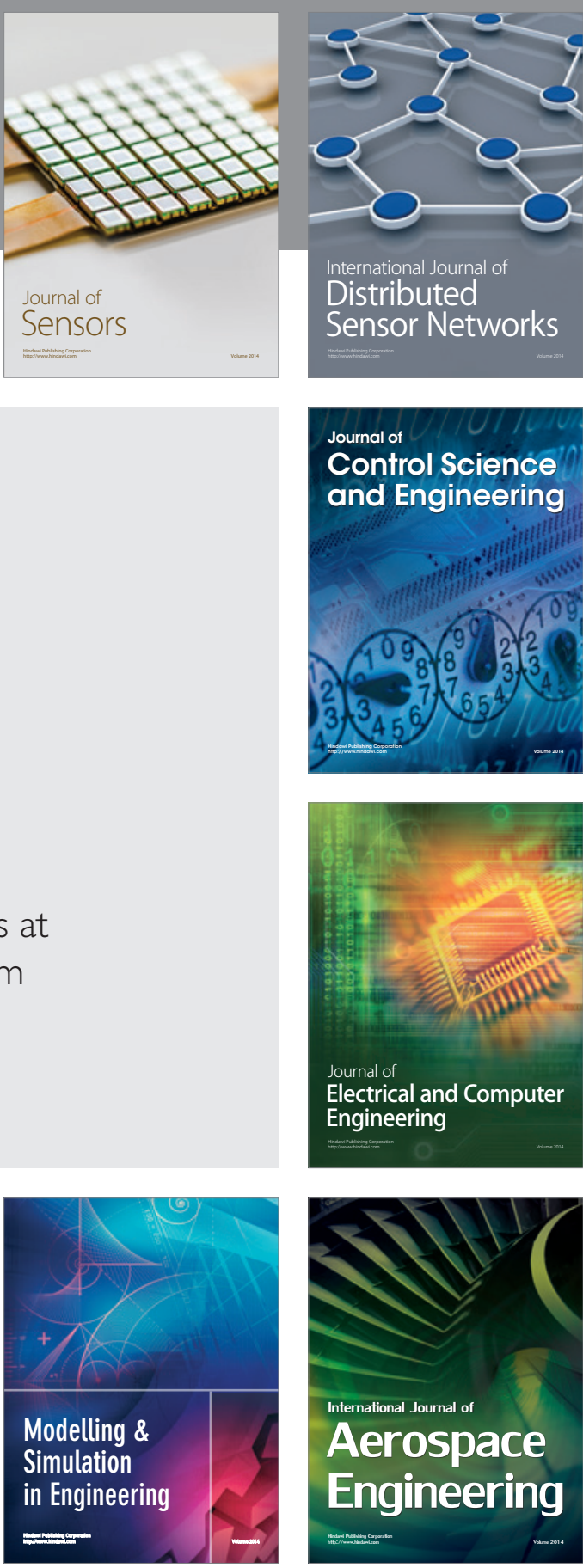

International Journal of

Distributed

Sensor Networks

Journal of

Control Science

and Engineering
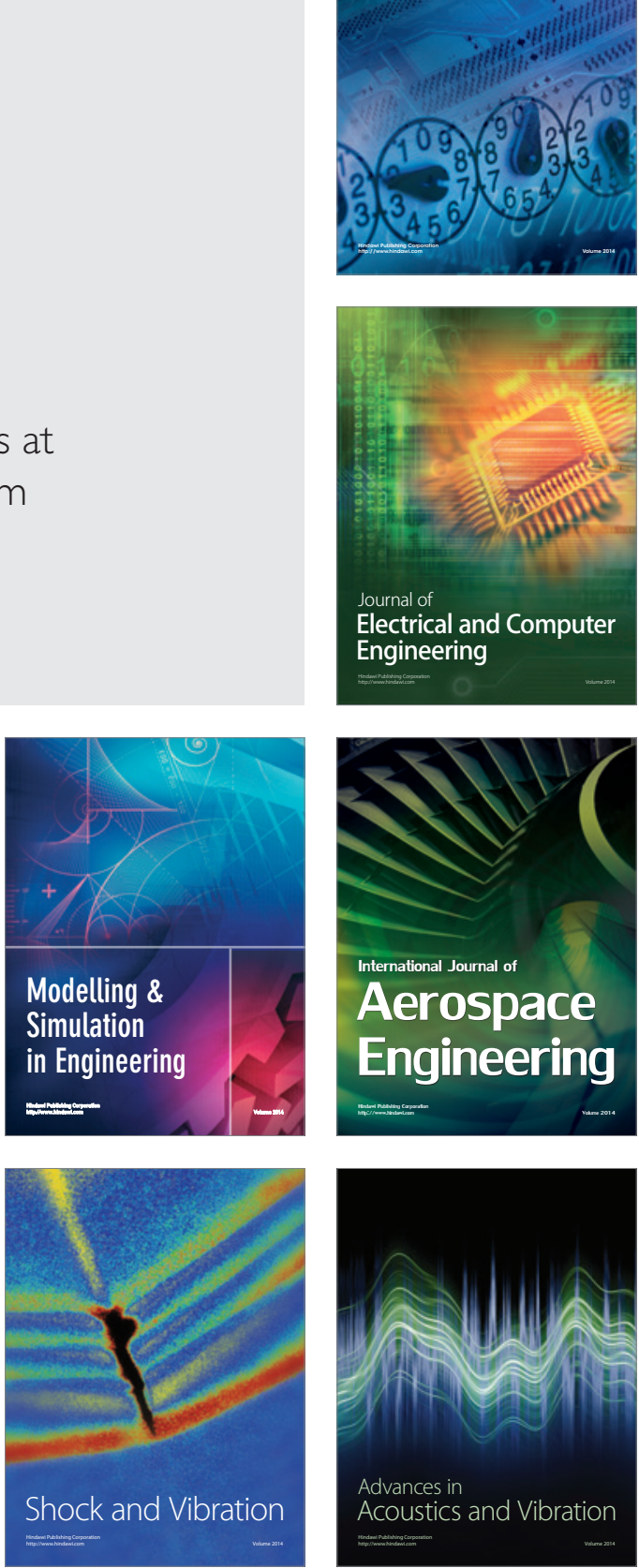